\title{
Global and regional estimates of COPD prevalence: Systematic review and meta-analysis
}

\author{
Davies Adeloye, Stephen \\ Chua, Chinwei Lee, Catriona \\ Basquill, Angeliki Papana, Evropi \\ Theodoratou, Harish Nair, Danijela \\ Gasevic, Devi Sridhar, Harry \\ Campbell, Kit Yee Chan, Aziz \\ Sheikh, Igor Rudan; Global Health \\ Epidemiology Reference Group \\ (GHERG)
}

Centre for Global Health Research and WHO Collaborating Centre for Population Health Research and Training, The Usher Institute for Population Health Sciences and Informatics, University of Edinburgh, Scotland, UK
Background The burden of chronic obstructive pulmonary disease (COPD) across many world regions is high. We aim to estimate COPD prevalence and number of disease cases for the years 1990 and 2010 across world regions based on the best available evidence in publicly accessible scientific databases.

Methods We conducted a systematic search of Medline, EMBASE and Global Health for original, population-based studies providing spirometry-based prevalence rates of COPD across the world from January 1990 to December 2014. Random effects meta-analysis was conducted on extracted crude prevalence rates of COPD, with overall summaries of the meta-estimates (and confidence intervals) reported separately for World Health Organization (WHO) regions, the World Bank's income categories and settings (urban and rural). We developed a meta-regression epidemiological model that we used to estimate the prevalence of COPD in people aged 30 years or more.

Findings Our search returned 37472 publications. A total of 123 studies based on a spirometry-defined prevalence were retained for the review. From the meta-regression epidemiological model, we estimated about 227.3 million COPD cases in the year 1990 among people aged 30 years or more, corresponding to a global prevalence of $10.7 \%$ (95\% confidence interval (CI) $7.3 \%-14.0 \%$ ) in this age group. The number of COPD cases increased to 384 million in 2010, with a global prevalence of $11.7 \%$ (8.4\%-15.0\%). This increase of $68.9 \%$ was mainly driven by global demographic changes. Across WHO regions, the highest prevalence was estimated in the Americas (13.3\% in 1990 and 15.2\% in 2010), and the lowest in South East Asia (7.9\% in 1990 and 9.7\% in 2010). The percentage increase in COPD cases between 1990 and 2010 was the highest in the Eastern Mediterranean region (118.7\%), followed by the African region (102.1\%), while the European region recorded the lowest increase (22.5\%). In 1990, we estimated about 120.9 million COPD cases among urban dwellers (prevalence of 13.2\%) and 106.3 million cases among rural dwellers (prevalence of 8.8\%). In 2010, there were more than 230 million COPD cases among urban dwellers (prevalence of $13.6 \%$ ) and 153.7 million among rural dwellers (prevalence of $9.7 \%$ ). The overall prevalence in men aged 30 years or more was $14.3 \%$ (95\% CI $13.3 \%-15.3 \%$ ) compared to $7.6 \%$ (95\% CI $7.0 \%$ $8.2 \%)$ in women.

Conclusions Our findings suggest a high and growing prevalence of COPD, both globally and regionally. There is a paucity of studies in Africa, South East Asia and the Eastern Mediterranean region. There is a need for governments, policy makers and international organizations to consider strengthening collaborations to address COPD globally. 
In a follow-up to the 2011 United Nations (UN) high level political declaration on non-communicable diseases (NCDs) [1], the World Health Assembly, in 2012, endorsed a new health goal (the " 25 by 25 goal"), which focuses on reduction of premature deaths from COPD and other NCDs by $25 \%$ by the year 2025 [2]. Despite this initiative, experts have reported that COPD remains a growing [3], but neglected global epidemic [4]. The World Health Organization (WHO) estimated that there were about 62 million people with moderate to severe COPD in 2002, with the total number of COPD cases predicted to increase to about 200 million in 2010 [5,6]. According to the 2010 Global Burden of Disease (GBD) study, COPD was responsible for about $5 \%$ of global disability-adjusted life years - DALYs (76.7 million) - and 5\% of total deaths (2.9 million) $[7,8]$. COPD is currently rated the fourth most common specific cause of death globally and predicted to be the third by 2030, in the absence of interventions that address the risks - especially tobacco smoking, exposures to combustion products of biomass fuels and environmental pollution $[9,10]$.

The burden of COPD has been reported to be high in some high-income countries (HIC), particularly due to high prevalence of smoking in these settings [11]. For example, between years 2000 and 2010 , about $4 \%-10 \%$ of adults were diagnosed with non-reversible and progressive airway obstruction (a basic feature of COPD) in populationbased surveys across many European countries, with smoking indicated as a major risk [12]. The WHO has estimated that in many HIC up to $73 \%$ of COPD deaths are related to tobacco smoking [6]. The European Union (EU) reported that the direct cost from COPD was over 38.6 billion Euros in 2005, representing about 3\% of total health care expenditure $[13,14]$. In the United States (US), over 2.7 million adults were estimated to have COPD in 2011, with about 135000 deaths reported [15]. In 2010, the US government spent nearly US $\$ 49.9$ billion on COPD, including 29.5 billion spent on direct health care, 8.0 billion on indirect morbidity and 12.4 billion on indirect mortality costs, respectively [15].

Meanwhile, it has been estimated that despite a high prevalence of COPD in some HIC, 90\% of COPD deaths still occur in low- and middle-income countries (LMIC) [4] and $40 \%$ of these deaths are attributable to smoking [6]. The burden in LMIC has been comparatively high owing to relatively low COPD awareness, challenges with COPD diagnosis and increased exposures to additional risk factors, especially combustion products of biomass fuels [16]. Salvi and colleagues reported that about 3 billion people globally are exposed to smoke from biomass fuel, compared to 1 billion people who smoke tobacco globally [17]. In many developing countries COPD is neglected by governments, physi- cians, experts and the pharmaceutical industry, although it's been identified as an important public health problem [4].

In the last two decades, the Burden of Obstructive Lung Disease (BOLD) initiative has been collecting country-specific data on the prevalence, risk factors and socioeconomic burden of COPD, using standardized and tested methods for conducting COPD surveys in the general population [18]. This is expected to provide governments of many nations with country-specific evidence on which to develop policy on COPD prevention and management [18]. As noted above, this initiative is yet to take a full effect in many LMIC [19]. In addition, spirometry (the gold standard for COPD diagnosis) is not widely available in many LMIC [16]. Even when it is there, professionals in LMIC are often not being trained properly on how to use spirometers or interpret spirometry results. There is concern that COPD burden has been underestimated, owing to over-reliance on doctor's diagnosis, with many diagnoses not being based on spirometry and international diagnostic guidelines [20]. The lack of routine COPD data collation and effective health information management system in many LMIC also implies that these settings could have been grossly underrepresented in global burden of COPD estimates [11].

Some global and regional estimates of COPD burden have been published [1,21-23]. However, despite the fact that COPD is now prevalent in both HIC and LMIC, experts have raised concerns that reliable estimates of COPD prevalence are still few in many parts of the world. Moreover, many of the estimates are based on varying definitions and diagnostic criteria of COPD [9]. Also, some of the current estimates were reported before the BOLD surveys in several countries, thereby failing to account for the additional spirometry-based epidemiological data from the BOLD surveys. There is a need for a revised and updated estimate of COPD prevalence across world regions. We conducted a systematic review of COPD prevalence based on spirometry data across world regions. Our aim was to provide global and regional prevalence rates of COPD that could facilitate adequate policy response in these regions.

\section{METHODS}

\section{Search strategy and selection criteria}

After identifying relevant Medical Subject Headings (MeSH), we conducted a systematic search of Medline, EMBASE and Global Health for studies estimating the prevalence of COPD globally from January 1990 to December 2014. We also searched Google Scholar for unpublished studies. Reference lists of retained publications were further hand-searched for studies omitted in our initial searches (see search terms in Tables sl-3 in Online Supplementary Document). 
We included original population-based (cohort or crosssectional) studies conducted worldwide. The retained studies provided estimates of the prevalence and number of cases of COPD and/or relevant population-based information from which COPD prevalence could be estimated. We excluded studies that had unclear study designs and methodologies, conducted before 1990, on non-human subjects, and that were reviews, viewpoints or editorials. No language restrictions were applied.

\section{Case definitions}

Based on an understanding of the diagnosis of COPD as reported by respiratory physicians, we included only studies that were based on spirometry, as these have been shown to be consistent with the diagnosis of COPD worldwide $[24,25]$. However, it is important to note that experts may still not fully agree on the spirometry-based definition that best defines COPD [26]. In 2001, the Global initiative on Obstructive Lung Disease (GOLD) recommended using the ratio of forced expiratory volume in one second $\left(\mathrm{FEV}_{1}\right)$ to forced vital capacity (FVC) that is less than $70 \%$ in the diagnosis of COPD ( $\left.\mathrm{FEV}_{1} / \mathrm{FVC}<70 \%\right)[25,27]$. This diagnostic criterion was also endorsed by the American Thoracic Society (ATS) and the European Respiratory Society (ERS) in 2004 [28]. It has been acknowledged that this criterion is simple and independent of reference equations [26]. However, the use of a fixed $\mathrm{FEV}_{1} / \mathrm{FVC}$ ratio has been debated from a number of perspectives [29-32], which we summarized in the discussion (see later). For the current study, we selected studies that used case definitions for COPD as shown in detail in Table $\mathbf{1}$.

\section{Data extraction, synthesis of results and analysis}

All extracted data were stored in Microsoft Excel file format. A parallel search and extraction was conducted by three independent reviewers (SC, CL and CB). Any disagreement between the three reviewers over article inclusion, exclusion and/or data extraction for the current study was resolved through re-review of their work and agreement between their two supervisors (DA and IR). We did not calculate Kappa statistics for the agreement between all reviewers because it was not amenable to straightforward computation and interpretation in this two-stage extraction process, which was based on a mix of independent review and collaborative re-review. Also, we did not make any attempts to contact the authors of studies that were rejected based on unclear reporting. Data were abstracted systematically on sample size, mean age, number of COPD cases, and the respective age- and sex-specific prevalence rates. These were classified into WHO regions, the World Bank's income categories, and study setting (urban, rural or mixed). For studies conducted on the same study site, pop-
Table 1. Basic characteristics of the studies retained for the analyses (a total of 140 study sites from 123 studies)

Characteristics STUDY SIIES

WHO regions:

\begin{tabular}{lc}
\hline AFRO & 6 \\
\hline AMRO & 15 \\
\hline EMRO & 7 \\
\hline EURO & 64 \\
\hline SEARO & 6 \\
\hline WPRO & 42 \\
\hline Income category:
\end{tabular}

Income category:

\begin{tabular}{ll}
\hline High & 87 \\
\hline Low and middle & 53
\end{tabular}

Settings:

Mixed*

\begin{tabular}{ll}
\hline Urban & 52 \\
\hline Rural
\end{tabular}

Rural 25

Study period:

\begin{tabular}{lc}
\hline $1990-1999$ & 24 \\
\hline $2000-2009$ & 94 \\
\hline $2010-$ present & 22 \\
\hline COPD case definitions: & 130 \\
\hline FEV $_{1} /$ FVC $<70 \%$ & 8 \\
\hline FEV $_{1} /$ FVC $<$ LLN & 1 \\
\hline FEV $_{1} /$ FVC $<75 \%$ & 1 \\
\hline FEV $_{1} /$ FVC $\leq 65 \%$ &
\end{tabular}

COPD - chronic obstructive pulmonary disease, FEV - forced expiratory volume, FVC - forced vital capacity, LLN - lower limit of normal

*Studies presenting a joint COPD estimate for urban and rural settings.

ulation or cohort, the first chronologically published study was selected, and all additional data from other studies were included in the selected paper. All extracted information from the retained studies is available in Table s4 in

\section{Online Supplementary Document.}

A random effect meta-analysis (DerSimonian and Laird method) was conducted on extracted crude prevalence rates of COPD [33]. Overall summaries of the meta-estimates (and confidence intervals) were reported separately for the WHO regions, the World Bank's income categories, and study settings, all expressed as percentages.

We developed a meta-regression epidemiological model and applied this on crude prevalence rates of COPD. In this model, mean ages corresponding to each prevalence rate were plotted on the $x$-axis (independent variable) and crude prevalence rates were plotted on the $y$-axis (dependent variable). We accounted for variation in sample sizes from each data point and controlled for year of publication to generate estimates of COPD prevalence for the years 1990 and 2000, respectively. The best fit was then used in our model and the equation generated from the fitted line was applied to the respective midpoints of the United Nations (UN) 5-year age-group population estimates for the years 1990 and 2010, respectively (United Nations, 2013). This enabled us to determine the prevalence of COPD glob- 
ally and in the WHO regions. A detailed description of our model has been explained in our previous study where we estimated the burden of COPD in Africa [34]. All analyses were conducted in Stata 13.1 (Stata Corp LP, College Station, Texas, USA).

\section{RESULTS}

\section{Systematic review}

Our search returned 37472 publications: 10828 in Medline, 24265 in EMBASE and 2379 in Global Health. A further three studies were included from other sources (Google Scholar and hand-searching reference list of relevant publications). 23457 studies remained after removing duplicates. After screening titles for relevance (studies estimating the burden of COPD) 21762 studies were excluded. We therefore assessed 1694 full-text papers. After applying the quality criteria, 1566 studies were excluded. This is because 934 articles did not provide prevalence data on COPD, population figures or relevant estimates from which prevalence can be calculated; further 325 articles did not specify study designs; and 307 studies were not based on spirometry and/or clarify COPD case definitions. A total of 128 studies were retained for the review, with 123 providing quantitative data for a total of 140 study settings (see

Figure $\mathbf{1}$ for the PRISMA flow diagram of study selection).

\section{Study characteristics}

The retained studies [23,26,35-155] were conducted across 140 locations spread across the six regions of the WHO (see Table s4 in Online Supplementary Document). European (EURO) and Western Pacific (WPRO) regions had the highest number of studies with 64 and 42 study sites, respectively. This was followed by the American region (AMRO) with 15 study sites. Eastern Mediterranean region (EMRO) had seven study sites, while the African region (AFRO) and South East Asia region (SEARO) each had six study sites (Table $\mathbf{1}$ ). Five studies were conducted in multiple sites. They included the BOLD study [40], European Community of Respiratory Health Survey (ECRHS) [113], the PLATINO study in Latin America [23] and two other studies in Europe $[61,89]$.

A total of 52 countries were represented, with China contributing the largest number of studies (22 in total). The mean age across studies was 54.1 years, ranging from 32 to 74 years. The total population from all studies was 877566. The COPD survey guidelines employed across selected studies included GOLD, ATS, ATS/ERS and the British Thoracic Society (BTS) (see Table s4 in Online Supplementary Document). However, COPD diagnosis was based on the diagnostic criterion of $\mathrm{FEV}_{1} / \mathrm{FVC}<70 \%$ in $92.2 \%$ of all retained studies (see Table $\mathbf{1}$ and Table s4 in Online Supplementary Document for detailed explanation of characteristics of selected studies).

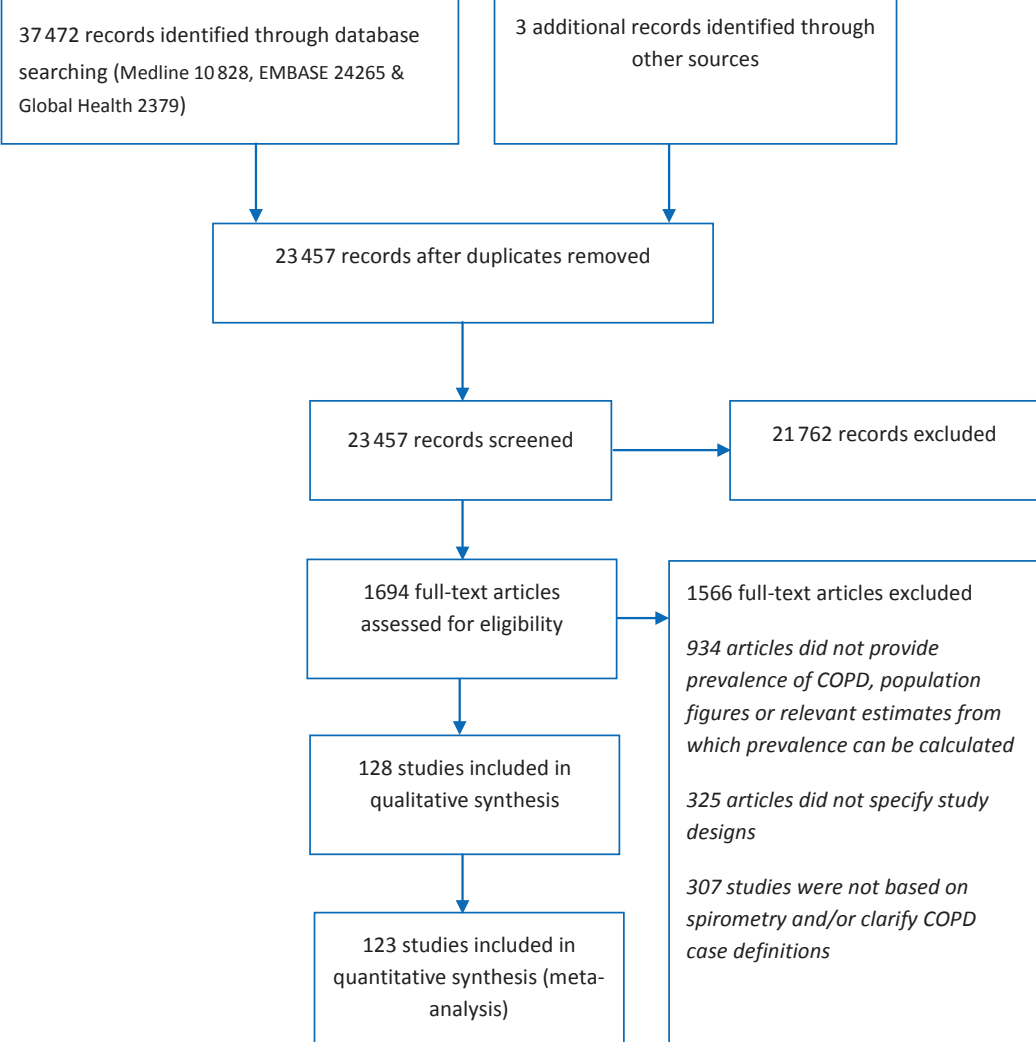

Figure 1. PRISMA flowchart of study selection. 


\section{Meta-estimates from crude COPD prevalence rates}

Forest plots were used to give a visual assessment of the pooled crude prevalence along with $95 \%$ confidence intervals of COPD by WHO regions, by study settings, and by the World Bank income category (Figures 2-4). We used the $\mathrm{I}^{2}$-statistic to evaluate heterogeneity in COPD prevalence between the retained studies. From the random effects meta-analysis, a prevalence of $11.4 \%$ (CI: $10.8 \%$ $12.0 \%$ ) was estimated globally in people aged $\geq 30$ years (Figure 2). The overall prevalence was higher among men (14.3\%; CI: 13.3\%-15.3\%) than women (7.6\%; CI: $7.0 \%-$ $8.2 \%$ ) (Table 2).

Among the WHO regions, AMRO region had the highest prevalence (14.1\%; CI: 11.4\%-16.7\%), followed by EMRO (13.2\%; CI: 8.8\%-17.7\%) and EURO (12.0\%; CI: 10.7\%$13.2 \%)$. AFRO had an estimated prevalence of $10.6 \%$ (CI: $6.1 \%-15.1 \%$ ) and WPRO of $10.0 \%$ (CI: 9.0\%-11.0\%). SEARO had the lowest prevalence of $7.8 \%$ (CI: $5.3 \%$ 10.4\%) (Figure 2 and Table 2).

Across most settings, urban dwellers had higher COPD prevalence rates (13.2\%; CI: $11.8 \%-14.7 \%$ ) than rural populations (10.2\%; 8.2\%-12.2\%) (Figure 3 and Table 2 ). An analysis according to the World Bank's income categories revealed that the prevalence was higher in high-income countries (HIC): 12.0\% (CI: 11.0\%-13.0\%), compared to $10.6 \%$ (CI: 9.5\%-11.6\%) in LMIC (Figure 4 and Table 2).

\section{Modelled estimates of COPD prevalence and number of cases}

The initial meta-regression analysis showed a significant effect of mean age and the year of study on estimated
Table 2. Summary of pooled crude COPD prevalence from selected studies (prevalence expressed in percentages for the population aged 30 years or older)

\begin{tabular}{llll} 
& BOTH SEXES (95\% CI) & MEN (95\% CI) & WoMEN (95\% CI) \\
World & $11.4(10.8-12.0)$ & $14.3(13.3-15.3)$ & $7.6(7.0-8.2)$ \\
\hline WHO region: & & & \\
\hline AFRO & $10.6(6.1-15.1)$ & $15.1(8.8-21.3)$ & $8.0(4.1-11.9)$ \\
\hline AMRO & $14.1(11.4-16.7)$ & $17.6(14.6-20.6)$ & $11.8(9.7-13.9)$ \\
\hline EMRO & $13.2(8.8-17.7)$ & $15.3(5.9-24.7)$ & $6.0(2.5-9.5)$ \\
\hline EURO & $12.0(10.7-13.2)$ & $13.7(12.0-15.3)$ & $7.6(6.8-8.5)$ \\
\hline SEARO & $7.8(5.3-10.4)$ & $9.3(4.7-13.9)$ & $3.6(2.4-4.9)$ \\
\hline WPRO & $10.0(9.0-11.0)$ & $14.4(12.5-16.3)$ & $6.4(5.3-7.5)$ \\
\hline Study setting: & $9.7(8.9-10.5)$ & $13.2(11.8-14.6)$ & $5.7(5.3-6.2)$ \\
\hline Mixed* & $13.2(11.8-14.7)$ & $15.7(13.7-17.7)$ & $9.4(8.3-10.6)$ \\
\hline Urban & $10.2(8.2-12.2)$ & $13.1(8.5-17.7)$ & $6.3(4.4-8.2)$ \\
\hline Rural & & & \\
\hline Income category: & $12.0(11.0-13.0)$ & $14.3(13.0-15.6)$ & $8.1(7.3-8.8)$ \\
\hline High & $10.6(9.5-11.6)$ & $14.5(12.3-16.7)$ & $6.5(5.8-7.2)$ \\
\hline Low and middle
\end{tabular}

COPD - chronic obstructive pulmonary disease, CI - confidence interval * Studies presenting a joint COPD estimate for urban and rural settings.

COPD prevalence rates. We therefore controlled for these effects in the model (Figure 5 and Table 3) [34]. From the model based on meta-regression we estimated about 227.3 million COPD cases in the year 1990 among people aged 30 years or more, corresponding to the global prevalence of $10.7 \%(7.3 \%-14.0 \%)$ in this age group. However, the number increased to 384 million COPD cases in 2010, corresponding to the global prevalence of $11.7 \%(8.4 \%-$ $15.0 \%$ ). This is an increase of $68.9 \%$ and it is driven mainly by the global demographic changes over the 20-year period (Table 4).

Based on the UN percentage of people living in urban areas in 1990 (43.0\%) and 2010 (51.6\%) [156], we estimated the global population in these regions in those two years.

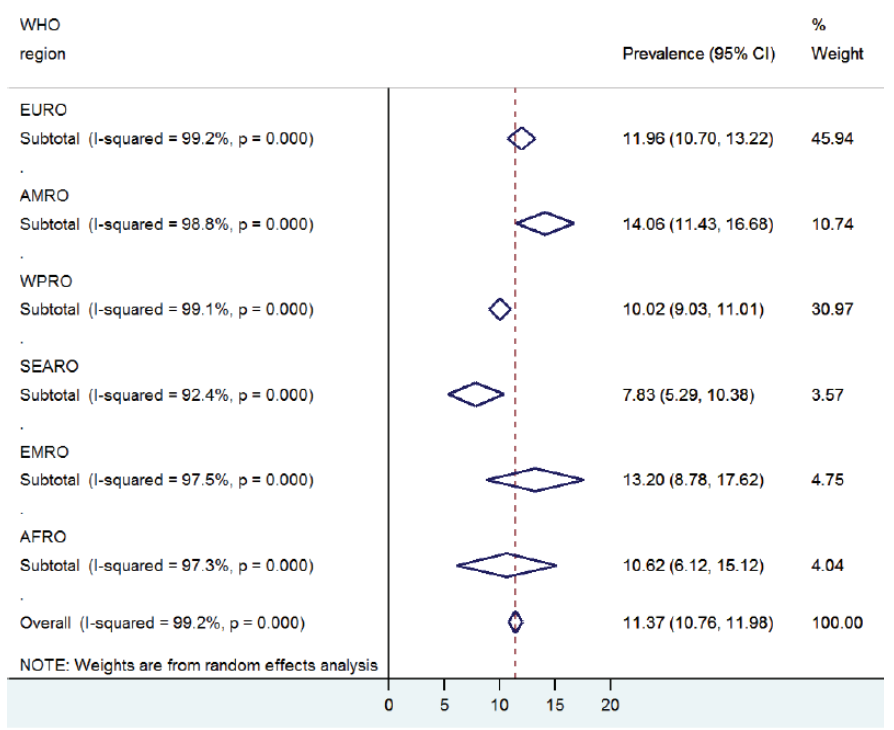

Figure 2. Overall pooled crude prevalence of COPD by WHO regions. 


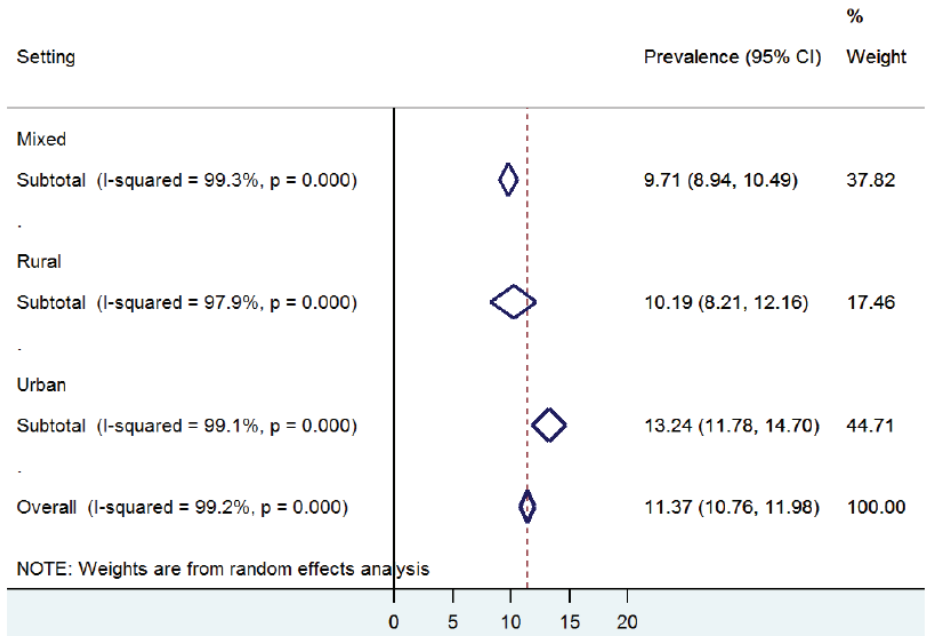

Figure 3. Overall pooled crude prevalence of COPD by study settings.

Table 3. Summary of meta-regression analysis

\begin{tabular}{|c|c|c|c|c|c|c|}
\hline Prevalence & Coefficient & SE & I & $P>I$ & $\begin{array}{c}95 \% \text { CI } \\
\text { LOWER }\end{array}$ & $\begin{array}{l}95 \% \text { CI } \\
\text { UPPER }\end{array}$ \\
\hline Age & & & & & 0.0410 & 0.2913 \\
\hline Year & 0.0447 & 0.0923 & 0.48 & 0.629 & -0.1377 & 0.2272 \\
\hline Const & -87.1297 & 184.5720 & -0.47 & 0.638 & -452.1321 & 277.8727 \\
\hline
\end{tabular}

CI - confidence interval

Our model revealed higher prevalence and number of COPD cases among urban dwellers. In 1990, we estimated about 120.9 million COPD cases among people aged 30 years or more, accounting for a prevalence of $13.2 \%$ $(10.0 \%-16.4 \%)$. At the same time, rural dwellers had 106.3 million cases, accounting for a prevalence of $8.8 \%$ $(6.5 \%-11.1 \%)$. By the year 2010 , the number of COPD cases among urban dwellers rose to more than 230 million, accounting for a prevalence of $13.6 \%(11.2 \%-16.9 \%)$, and about 153.7 million cases among rural dwellers, accounting for a prevalence of $9.7 \%(7.6 \%-11.8 \%)$. The percentage of increase in COPD cases between 1990 and 2010 was higher among urban dwellers than among rural residents (90.5\% vs $44.6 \%$, respectively) (Table 5 ).

\section{DISCUSSION}

This study is among the first systematic attempts to estimate the prevalence of COPD across the world regions using spirometry-based data. The estimates presented here are based on the age range starting from 30 years, while many of the previous reviews were based on people aged 40 years or older. An appreciable prevalence of COPD has been reported in younger population groups, adding to uncertainties over the current epidemiological situation globally.

In the current study, we estimated a global prevalence of $10.7 \%(7.3 \%-14.0 \%)$ in 1990 and $11.7 \%(8.4 \%-15.0 \%)$ in
2010, corresponding to 227 and 384 million of affected cases in 1990 and 2010, respectively. This estimate is an order of magnitude higher than the one presented in the 2001 World Health Report, estimating a world-wide prevalence of COPD of 10.1 per 1000 population (12.1 per 1000 men and 8.1 per 1000 women) [157]. A 2006 global review conducted by Halbert and colleagues reported a pooled prevalence of $9.2 \%$ (7.2-11.0), based on 26 spirometry-based estimates - a figure much closer to our estimates [21]. In the 2005 BOLD study, conducted in 12 sites globally and based on post-bronchodilator $\mathrm{FEV}_{1} / \mathrm{FVC}<70 \%$, the overall prevalence of Stage II or higher COPD was 10.1\% (men 11.8\% and women $8.5 \%$ ) [40], which is again much closer to our results. Given that the estimates presented in the 2001 World Health Report were based on doctor's diagnosis and included all ages, this may explain the departure from spirometrybased estimates. All spirometry-based estimates to date seem to be comparable and may be indicative of the usefulness of spirometry as a gold standard for COPD diagnosis in population-based studies.

The highest COPD prevalence estimated in this study was observed in the American region, with an estimated prevalence of $13.3 \%$ and $15.2 \%$ in 1990 and 2010 , respectively. Moreover, we estimated that 113 million COPD cases should be expected in Western Pacific region in 2010, almost doubling the estimated for 1990 which stood at 60 million. In the South East Asia, we estimated about 66.4 million COPD cases in 2010. Comparing our results to other estimates from previous studies, in the PLATINO multicentre study conducted across five South-American cities, which applied the same survey approach as the 2005 BOLD study, crude prevalence of COPD ranged from $7.8 \%$ in Mexico city to 19.7\% in Montevideo [23]. A total of 12.2 million COPD cases, corresponding to an overall prevalence of $14.3 \%$, was estimated for the urban population 


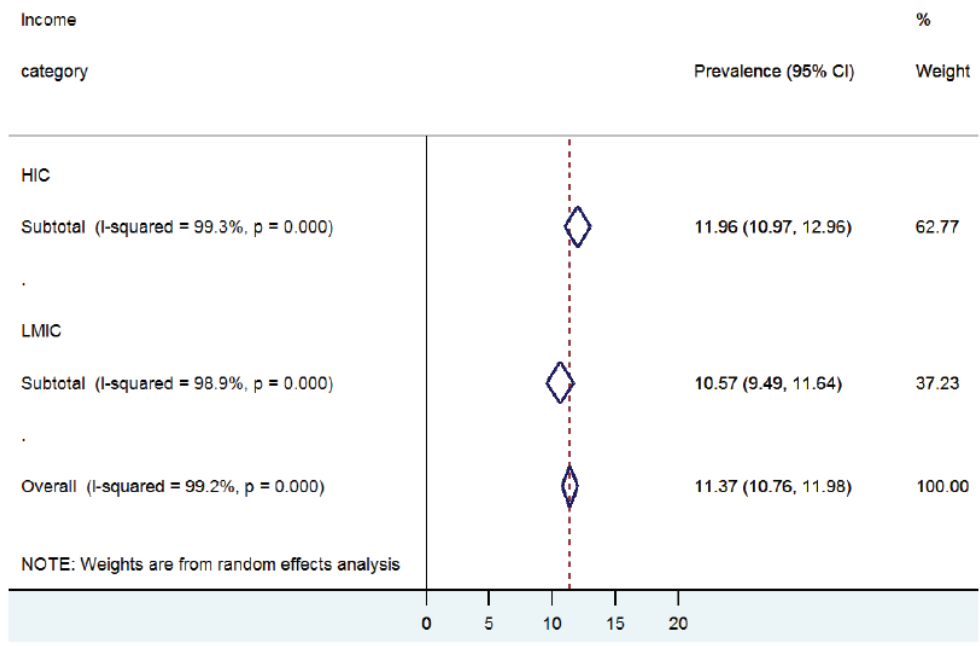

Figure 4. Overall pooled crude prevalence of COPD by World Bank income category.

Table 4. Summary of overall COPD cases and prevalence rates in people aged 30 years or more (estimates derived from epidemiological model)

\begin{tabular}{|c|c|c|c|c|c|}
\hline & & & & & \% INCREASE IN COPD CASES \\
\hline & Cases (millions) & Prevalence (\%) & Cases (millions) & Prevalence (\%) & \\
\hline World & 227.3 & $10.7(7.3-14.0)$ & 384.0 & $11.7(8.4-15.0)$ & 68.9 \\
\hline AFRO & 14.1 & $9.8(8.9-10.7)$ & 28.5 & $11.4(10.5-12.3)$ & 102.1 \\
\hline AMRO & 41.6 & $13.3(12.9-13.7)$ & 72.0 & $15.2(14.9-15.5)$ & 73.1 \\
\hline EMRO & 13.4 & $11.8(10.1-13.5)$ & 29.3 & $13.4(11.8-15.1)$ & 118.7 \\
\hline EURO & 54.2 & $11.8(11.6-12.0)$ & 66.4 & $13.7(13.5-13.9)$ & 22.5 \\
\hline SEARO & 44.5 & $7.9(7.5-8.4)$ & 75.1 & $9.7(9.3-10.1)$ & 68.8 \\
\hline WPRO & 59.5 & $9.2(9.0-9.4)$ & 112.7 & $11.1(10.9-11.3)$ & 89.4 \\
\hline Urban & 120.9 & $13.2(10.0-16.4)$ & 230.3 & $13.6(11.2-16.9)$ & 90.5 \\
\hline Rural & 106.3 & $8.8(6.5-11.1)$ & 153.7 & $9.7(7.6-11.8)$ & 44.6 \\
\hline
\end{tabular}

COPD - chronic obstructive pulmonary disease

[23]. A mathematical model derived from prevalence of known COPD risk factors in 12 Asia-Pacific sites estimated about 57 million moderate-to-severe COPD cases in people aged 30 years or more in 2002, which is equivalent to a prevalence of $6.3 \%$ in the Asia Pacific region [158]. This figure is considerably larger than the WHO estimate for the region, which stood at 3.9\% [157]. In addition, the regional working group reported that the number of COPD cases in China in 2002 should be expected to reach 38.2 million, with a prevalence of $6.5 \%$ [158]. This is again about 2.5 times higher than the estimates reported by the WHO [157]. Such differences in the regional pooled prevalence rates reported by separate authors may be linked to heterogeneities arising from differences in survey methodologies, population structure, subject's age and case identification [159]. Moreover, experts have reported that despite the apparently large burden of COPD in Western Pacific and South East Asia, there are few good epidemiological surveys on COPD in these regions [22]. For example, in a recent review in India, McKay and colleagues re- ported that they could not identify a single high quality study that provided detailed estimate of COPD prevalence using a relatively standard spirometry-based definition, and were therefore unable to perform a meta-analysis [160]. This was also observed in our study, as there were only three studies retained in India with only two of these providing age- and sex-specific COPD prevalence rates. However, we managed to include several large epidemiological surveys conducted in China, which actually had the highest number of retained studies (22 studies) of all the 52 countries represented (see Table 44 in Online Supplementary Document).

In the WHO EURO region, we noted the lowest increase in total number of COPD cases between 1990 and 2010 (22\%). This may reflect the reduction in prevalence of smoking in Europe through intensive public health measures and legal regulations. According to the European Health Interview Survey (EHIS), the prevalence of COPD in 2008 among people aged at least 15 years in $16 \mathrm{EU}$ member states ranged from $1.2 \%$ to $6.2 \%$, with a mean 


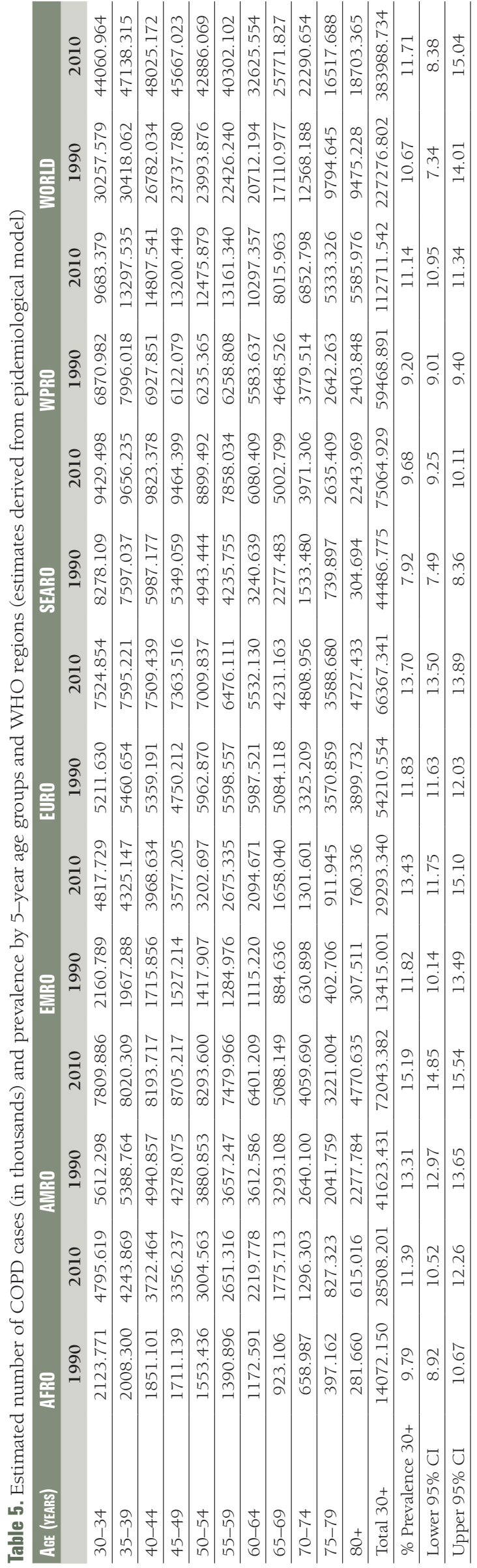

prevalence of 3.1\% [161], but EHIS was based on patient's self-reported diagnosis of COPD. Experts have raised concerns that COPD is often under-diagnosed when based on self-reporting of COPD diagnosis, even in high-income settings, and that the true prevalence rates may be considerably higher [162].

Several authors have reported that the epidemiological evidence on COPD in African region is still very limited and that this has affected the response to its growing burden in the region $[16,34,163,164]$. We estimated a prevalence of about $11 \%$ in 2010 , amounting to 29 million COPD cases in the region. This is similar to a recent continent-wide estimate of more than 26 million cases in 2010 [34]. Epidemiological data are also very limited in the Middle East and North Africa [165]. Based on scarce available evidence, it appears that the EMR had the lowest absolute number of COPD cases in 1990 among the world regions, with 13 million (prevalence of 12\%). However, the region then recorded the highest percentage increase by the year 2010 of $119 \%$. Smoking rates in the Middle East and in many Mediterranean countries have reportedly been high [165]. This may imply that the burden of COPD in EMRO region could have been considerably under-estimated in the year 1990 .

Several studies reported that urbanization is an important risk in the development of COPD [9,39]. We estimated over 230 million cases of COPD among global urban dwellers in 2010 , accounting for almost $60 \%$ of all COPD cases. The rapid rate of urbanization in many parts of the world, especially in LMIC, may contribute to an increasing prevalence of COPD globally [39]. Moreover, the prevalence of COPD among men was consistently higher than in women across all world regions, settings and income categories. Some authors question the independent etiological role of gender in the development of COPD [166], given that the risk profile among men favours the development of disease. Recent reviews suggested that increased tobacco use among women in high-income countries and the higher risk of exposure to indoor air pollution (such as biomass fuels used for cooking and heating) in low- and middle income countries may contribute to reducing gender differences in COPD in future [1].

Our study has a number of limitations. Although we identified a considerable number of studies for this review, they were not proportionately distributed across the WHO regions, nor were the sample sizes from the regions proportional to regional populations. More than $46 \%$ of the data points were from the European region, meaning that the overall results may over-represent the burden of COPD in Europe. On the other hand, African region (4\%), South East Asian region (4\%) and Eastern Mediterranean region (5\%) are all grossly under-represented, highlighting the lack of good quality prevalence data outside of the highincome countries.

Another important limitation relates to the differences in case definitions and diagnostic guidelines employed across 


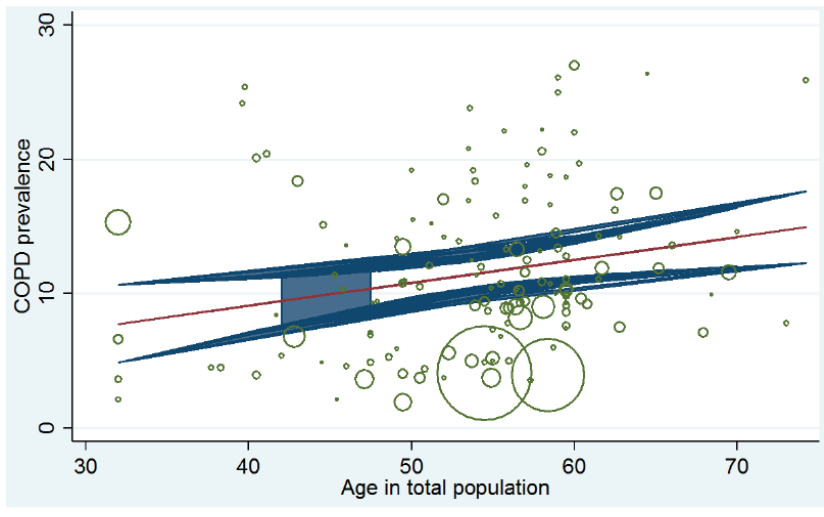

Figure 5. Epidemiological model based on meta-regression: The model is based on extracted crude COPD prevalence rates and adjusted for the study period and mean age of subjects from each study (the size of each bubble corresponds to the sample size from the respective study).

studies over time. In our analysis, we required spirometry as the standard diagnostic parameter, given the concerns raised over alternative definitions of COPD. Across all retained studies, the definition based on FEV/FVC $<70 \%$ was used in the large majority of studies, but this still does not address all possible sources of variation in case definition. Some authors even question the use of a fixed $\mathrm{FEV}_{1} / \mathrm{FVC}$ ratio mainly because it has no statistical basis and because choosing 0.7 as a cut, off point - instead of 0.68 or 0.72 , for example - is essentially arbitrary [29]. Experts have argued that this fixed criterion may potentially over-diagnose COPD in the elderly, as lung elasticity decreases with age, which reduces FEV ${ }_{1}$ more than FVC [30]. Hence, using a fixed ratio can result in under-diagnoses in younger patients, and more frequent diagnoses in the elderly. The use of a lower limit of normal (LLN) has been suggested instead, and this is described as the lower fifth percentile of a reference population [31]. It is calculated by subtracting the standard deviation (multiplied by 1.64) from the mean [31]. However, some studies suggest that LLN may miss subjects with COPD [32]. This variation in COPD diagnosis is especially pertinent in LMICs, where undiagnosed or poorly treated asthma, bronchiectasis, tuberculosis or some other obstructive airway disease may be more prevalent and possibly misdiagnosed as COPD [17]. Even when the FEV/FVC $<70 \%$ criterion was consistently applied, some studies were based on pre-bronchodilator values, rather than post-bronchodilator values, as recommended by
GOLD. In addition, it was often not fully explained how exactly was spirometry performed and what was the protocol. A number of technical issues could have affected the estimates, such as the choice of spirometer, the level of training of the operator, and the process of collection and storage of spirometry measurements. Finally, physicians' knowledge of guidelines can also pose a barrier to spirometry use in settings where it is available [167].

An additional limitation is associated with the choice of our epidemiological model, which was mainly based on age of the examinees. There are several other important predictors that could have been incorporated into the model if the information was available from the retained studies, including those related to study sites, income levels, smoking, socio-economic determinants of health, occupational exposures and others. However, the studies that we retained would rarely report these important covariates, so we could not use them in our model.

Meanwhile, it is worth noting that most of the studies (83\%) included in this review were published after the year 2000 , and encouragingly, the number of epidemiological studies focusing on COPD has been steadily increasing over the past two decades. This upward trend provides an indication of an increased awareness and recognition of COPD as a growing global health burden, and the need to strengthen research base and improve and standardize the methods.

Our findings suggest a high and growing prevalence of COPD, both globally and regionally, with substantial variation in trends between different world regions. The estimates presented here are consistent with other spirometrybased reviews on the burden of COPD. As with any other public health problem, increased political commitment and funding remains crucial, particularly in LMIC settings. Governments and policymakers must consider strengthening regulations to address occupational and environmental risk factors, regulate tobacco use and improve public awareness. A combined use of patient- and physician targeted educational interventions could also help [168]. The efforts of BOLD, aiming to standardize methodology and definitions, must be supported, and other research entities should strongly consider adopting similar methods or collaborating with BOLD in order to provide epidemiological results that are more comparable in and among populations. It is only through such concerted effort that the current high global COPD burden may be reduced in the coming decades. 
Funding: None.

Ethical approval: Not required.

Authorship declaration: IR and KYC conceptualized the study. SC, CL and CB conducted the literature review for all databases. DA and AP performed all statistical analyses. DA, IR and KYC drafted the paper, with help from SC, CL and CB. Then, ET, HN, DG, DS, HC and AS provided useful additional input into the first draft. They also contributed to writing of the final version of the paper and checked the paper for important intellectual content.

Declaration of interest. IR and HC are co-editors-in-chief of the Journal of Global Health. To ensure that any possible conflict of interest relevant to the journal has been addressed, this article was reviewed according to best practice guidelines of international editorial organizations. Authors have completed the Unified Competing Interest form at www.icmje.org/coi_disclosure.pdf (available on request from the corresponding author). None of the participating authors has a conflicting financial or other interest related to the work detailed in this manuscript.

1 Beaglehole R, Bonita R, Alleyne G, Horton R, Li L, Lincoln P, et al. UN High-Level Meeting on Non-Communicable Diseases: addressing four questions. Lancet. 2011;378:449-55. Medline:21665266 doi:10.1016/ S0140-6736(11)60879-9

2 Horton R. Non-communicable diseases: 2015 to 2025. Lancet. 2013;381:509-10. Medline:23410603 doi:10.1016/S0140-6736(13)60100-2

3 Mannino DM, Buist AS. Global burden of COPD: risk factors, prevalence, and future trends. Lancet. 2007;370:765-73. Medline:17765526 doi:10.1016/S0140-6736(07)61380-4

4 Barnes PJ. Chronic Obstructive Pulmonary Disease: A growing but neglected global epidemic. PLoS Med. 2007;4:e112. Medline:17503959 doi:10.1371/journal.pmed.0040112

5 World Health Organization. Global Burden of Disease (GBD) 2002 estimates. In: World Health Report 2004. Geneva: WHO, 2004. Available: http://www.who.int/healthinfo/global_burden_disease/estimates_regional_2002/en/. Accessed: 25 November 2015.

6 World Health Organization. Burden of COPD. Geneva: WHO, 2014. Available: http://www.who.int/respiratory/copd/burden/en/. Accessed: 25 November 2015.

7 Murray CJ, Vos T, Lozano R, Naghavi M, Flaxman AD, Michaud C, et al. Disability-adjusted life years (DALYs) for 291 diseases and injuries in 21 regions, 1990-2010: a systematic analysis for the Global Burden of Disease Study 2010. Lancet. 2012;380:2197-223. Medline:23245608

8 Lozano R, Naghavi M, Foreman K, Lim S, Shibuya K, Aboyans V, et al. Global and regional mortality from 235 causes of death for 20 age groups in 1990 and 2010: A systematic analysis for the Global Burden of Disease Study 2010. Lancet. 2012;380:2095-128. Medline:23245604 doi:10.1016/S0140-6736(12)61728-0

9 Lopez AD, Shibuya K, Rao C, Mathers CD, Hansell AL, Held LS, et al. Chronic obstructive pulmonary disease: current burden and future projections. Eur Respir J. 2006;27:397-412. Medline:16452599 doi:10.118 3/09031936.06.00025805

10 Mathers CD. Uncertainty and data availability for the global burden of disease estimates 2000-2002. In: Evidence and Information for Policy Working Paper. Geneva, Switzerland: WHO, 2005. Available: http://www. who.int/healthinfo/global_burden_disease/en/index.html. Accessed: 25 November 2015.

11 Pauwels RA, Rabe KF. Burden and clinical features of chronic obstructive pulmonary disease (COPD). Lancet. 2004;364:613-20. Medline:15313363 doi:10.1016/S0140-6736(04)16855-4

12 ECRHS. European Community Respiratory Health Survey 2012. Available: http://www.ecrhs.org/. Accessed: 25 November 2015.

13 European COPD Coalition. Prevalence in EU 2014. Available: http://www.copdcoalition.eu/about-copd/prevalence. Accessed: 25 November 2015.

14 Chapman KR, Mannino DM, Soriano JB, Vermeire PA, Buist AS, Thun MJ, et al. Epidemiology and costs of chronic obstructive pulmonary disease. Eur Respir J. 2006;27:188-207. Medline:16387952 doi:10.1183/09 031936.06.00024505

15 Centre for Disease Control. Chronic Obstructive Pulmonary Disease among adults — United States, 2011. MMWR Morb Mortal Wkly Rep. 2012;61:938-43. Medline:23169314

16 Mehrotra A, Oluwole AM, Gordon SB. The burden of COPD in Africa: a literature review and prospective survey of the availability of spirometry for COPD diagnosis in Africa. Trop Med Int Health. 2009;14:840-8. Medline:19702594 doi:10.1111/j.1365-3156.2009.02308.x

17 Salvi SS, Manap R, Beasley R. Understanding the true burden of COPD: the epidemiological challenges. Prim Care Respir J. 2012;21:249-51. Medline:22885564 doi:10.4104/pcrj.2012.00082

18 Buist AS, Vollmer WM, Sullivan SD, Weiss KB, Lee TA, Menezes AM, et al. The Burden of Obstructive Lung Disease Initiative (BOLD): rationale and design. COPD. 2005;2:277-83. Medline:17136954 doi:10.1081/ COPD-57610 
19 Burney P. The Burden of Obstructive Lung Disease (BOLD) study prepares for African surveys. Afr Health. 2011;33:12.

20 Kart L, Akkoyunlu ME, Bayram M, Yakar F, Kutbay Ozcelik H, Karakose F, et al. COPD: an underdiagnosed disease at hospital environment. Wien Klin Wochenschr. 2014;126:73-8. Medline:24249327 doi:10.1007/ s00508-013-0458-4

21 Halbert RJ, Natoli JL, Gano A, Badamgarav E, Buist AS, Mannino DM. Global burden of COPD: systematic review and meta-analysis. Eur Respir J. 2006;28:523-32. Medline:16611654 doi:10.1183/09031936.06.00 124605

22 Ko FWS, Hui DSC, Lai CKW. Worldwide burden of COPD in high-and low-income countries. Part III. AsiaPacific studies. Int J Tuberc Lung Dis. 2008;12:713-7. Medline:18544193

23 Menezes AMB, Perez-Padilla R, Jardim JRB, Muino A, Lopez MV, Valdivia G, et al. Chronic obstructive pulmonary disease in five Latin American cities (the PLATINO study): A prevalence study. Lancet. 2005;366:187581. Medline:16310554 doi:10.1016/S0140-6736(05)67632-5

24 Pauwels RA, Buist AS, Ma P, Jenkins CR, Hurd SS. Global strategy for the diagnosis, management, and prevention of chronic obstructive pulmonary disease: National Heart, Lung, and Blood Institute and World Health Organization Global Initiative for Chronic Obstructive Lung Disease (GOLD): executive summary. Respir Care. 2001;46:798-825. Medline:11463370

25 GOLD. Global Strategy for the Diagnosis, Management, and Prevention of Chronic Obstructive Pulmonary Disease. 2014. Available: http://www.goldcopd.org/uploads/users/files/GOLD_Report_2014_Jun11.pdf. Accessed: 25 November 2015.

26 Hwang YI, Kim CH, Kang H-R, Shin T, Park SM, Jang SH, et al. Comparison of the prevalence of Chronic Obstructive Pulmonary Disease diagnosed by lower limit of normal and fixed ratio criteria. J Korean Med Sci. 2009;24:621-6. Medline:19654942 doi:10.3346/jkms.2009.24.4.621

27 GOLD. 2005 Update: Executive summary, global strategy for the diagnosis, management and prevention of COPD. Washington, D.C.: Global Initiative for Chronic Obstructive Lung Disease; 2005. Available: http:// www.goldcopd.com. Accessed: 25 November 2015.

28 Celli BR, MacNee W. Standards for the diagnosis and treatment of patients with COPD: a summary of the ATS/ERS position paper. Eur Respir J. 2004;23:932-46. Medline:15219010 doi:10.1183/09031936.04.000 14304

29 Pellegrino R, Brusasco V, Viegi G, Crapo RO, Burgos F, Casaburi R, et al. Definition of COPD: based on evidence or opinion? Eur Respir J. 2008;31:681-2. Medline:18310402 doi:10.1183/09031936.00154307

30 Di Marco F, Tantucci C, Pellegrino G, Centanni S. Chronic obstructive pulmonary disease diagnosis: The simpler the better? Not always. Eur J Intern Med. 2013;24:199-202. Medline:23466208 doi:10.1016/j. ejim.2013.01.008

31 Mohamed Hoesein FAA, Zanen P, Lammers J-WJ. Lower limit of normal or FEV1/FVC $<0.70$ in diagnosing COPD: An evidence-based review. Respir Med. 2011;105:907-15. Medline:21295958 doi:10.1016/j. rmed.2011.01.008

32 Izquierdo Alonso JL, Ramos PDL, Glez-Moro JMR. The use of the lower limit of normal as a criterion for COPD excludes patients with increased morbidity and high consumption of health-care resources. Arch Bronconeumol. 2012;48:223-8. Medline:22480962 doi:10.1016/j.arbres.2012.02.007

33 DerSimonian R, Laird N. Meta-analysis in clinical trials. Control Clin Trials. 1986;7:177-88. Medline:3802833 doi:10.1016/0197-2456(86)90046-2

34 Adeloye D, Basquill C, Papana A, Chan KY, Rudan I, Campbell H. An Estimate of the Prevalence of COPD in Africa: A systematic analysis. COPD. 2015;12:71-81. Medline:24946179 doi:10.3109/15412555.2014.9 08834

35 Khelafi R, Aissanou A, Tarsift S, Skander F. Epidemiology of chronic obstructive pulmonary disease in Algiers. Rev Mal Respir. 2011;28:32-40. Medline:21277472 doi:10.1016/j.rmr.2010.06.026

36 Martins P, Rosado-Pinto J, Do Ceu Teixeira M, Neuparth N, Silva O, Tavares H, et al. Under-report and underdiagnosis of chronic respiratory diseases in an African country. Allergy. 2009;64:1061-7. Medline:19210360 doi:10.1111/j.1398-9995.2009.01956.x

37 Fullerton DG, Suseno A, Semple S, Kalambo F, Malamba R, White S, et al. Wood smoke exposure, poverty and impaired lung function in Malawian adults. Int J Tuberc Lung Dis. 2011;15:391-8. Medline:21333109

38 Gathuru IM, Bunker CH, Ukoli FA, Egbagbe EE. Differences in rates of obstructive lung disease between Africans and African Americans. Ethn Dis. 2002;12:S3-S107. Medline:12477165

39 Musafiri S, van Meerbeeck J, Musango L, Brusselle G, Joos G, Seminega B, et al. Prevalence of atopy, asthma and COPD in an urban and a rural area of an African country. Respir Med. 2011;105:1596-605. Medline:21783353 doi:10.1016/j.rmed.2011.06.013

40 Buist AS, McBurnie MA, Vollmer WM, Gillespie S, Burney P, Mannino DM, et al. International variation in the prevalence of COPD (The BOLD Study): a population-based prevalence study. Lancet. 2007;370:74150. Medline:17765523 doi:10.1016/S0140-6736(07)61377-4

41 Tan WC, Lo C, Jong A, Xing L, Fitzgerald MJ, Vollmer WM, et al. Marijuana and chronic obstructive lung disease: a population-based study. CMAJ. 2009;180:814-20. Medline:19364790 doi:10.1503/cmaj.081040 
42 Al-Hazmi M, Wooldrage K, Anthonisen N, Becklake M, Bowie D, Chan-Yeung M, et al. Airflow obstruction in young adults in Canada. Can Respir J. 2007;14:221-7. Medline:17551598

43 Tilert T, Dillon C, Paulose-Ram R, Hnizdo E, Doney B. Estimating the U.S. prevalence of chronic obstructive pulmonary disease using pre- and post-bronchodilator spirometry: The National Health and Nutrition Examination Survey (NHANES) 2007-2010. Respir Res. 2013;14:103. Medline:24107140 doi:10.1186/14659921-14-103

44 Methvin JN, Mannino DM, Casey BR. COPD prevalence in Southeastern Kentucky: The burden of lung disease study. Chest. 2009;135:102-7. Medline:18689574 doi:10.1378/chest.08-1315

45 Mannino DM, Homa DM, Akinbami LJ, Ford ES, Redd SC. Chronic Obstructive Pulmonary Disease Surveillance: United States, 1971-2000. MMWR Surveill Summ. 2002;51 S6:1-16. Medline:12198919

46 Ford ES, Mannino DM, Wheaton AG, Giles WH, Presley-Cantrell L, Croft JB. Trends in the prevalence of obstructive and restrictive lung function among adults in the United States: Findings from the national health and nutrition examination surveys from 1988-1994 to 2007-2010. Chest. 2013;143:1395-406. Medline:23715520 doi:10.1378/chest.12-1135

47 Vaz Fragoso CA, Concato J, McAvay G, Van Ness PH, Rochester CL, Yaggi HK, et al. The Ratio of FEV1 to FVC as a basis for establishing Chronic Obstructive Pulmonary Disease. Am J Respir Crit Care Med. 2010;181:446-51. Medline:20019341 doi:10.1164/rccm.200909-13660C

48 Menezes A, Macedo SC, Gigante DP, da Costa JD, Olinto MT, Fiss E, et al. Prevalence and risk factors for chronic obstructive pulmonary disease according to symptoms and spirometry. COPD. 2004;1:173-9. Medline:17136985 doi:10.1081/COPD-120039561

49 Caballero A, Torres-Duque CA, Jaramillo C, Bolivar F, Sanabria F, Osorio P, et al. Prevalence of COPD in five Colombian cities situated at low, medium, and high altitude (PREPOCOL study). Chest. 2008;133:343-9. Medline:17951621 doi:10.1378/chest.07-1361

50 Laniado-Laborin R. Smoking and Chronic Obstructive Pulmonary Disease (COPD). Parallel Epidemics of the 21st Century. Int J Environ Res Public Health. 2009;6:209-24. Medline:19440278 doi:10.3390/ijerph6010209

51 Amra B, Golshan M, Fietze I, Penzel T, Welte T. Correlation between chronic obstructive pulmonary disease and obstructive sleep apnea syndrome in a general population in Iran. J Res Med Sci. 2011;16:885-9. Medline:22279455

52 Golshan M, Barahimi H, Nasirian K. Prevalence of chronic bronchitis and chronic respiratory symptoms in adults over the age of 35 years in Isfahan, Iran in 1998. Respirology. 2001;6:231-5. Medline:11555382 doi:10.1046/j.1440-1843.2001.00331.x

53 Golshan M, Amra B, Welte T. Sample survey of chronic obstructive pulmonary disease and associated risk factors in Isfahan, Iran. Tanaffos. 2011;10:32-6. Medline:25191373

54 Waked M, Khayat G, Salameh P. Chronic obstructive pulmonary disease prevalence in Lebanon: A cross-sectional descriptive study. Clin Epidemiol. 2011;3:315-23. Medline:22253549 doi:10.2147/CLEP.S26350

55 Daldoul H, Denguezli M, Jithoo A, Gnatiuc L, Buist S, Burney P, et al. Prevalence of COPD and tobacco smoking in Tunisia — Results from the BOLD Study. Int J Environ Res Public Health. 2013;10:7257-71. Medline:24351745 doi:10.3390/ijerph10127257

56 Al Zaabi A, Asad F, Abdou J, Al Musaabi H, Al Saiari MB, Mohammed Buhussien AS, et al. Prevalence of COPD in Abu Dhabi, United Arab Emirates. Respir Med. 2011;105:566-70. Medline:21216136 doi:10.1016/j. rmed.2010.12.008

57 Al Ghobain M, Al-Hajjaj M, Wali S. Prevalence of chronic obstructive pulmonary disease among smokers attending primary healthcare clinics in Saudi Arabia. Ann Saudi Med. 2011;31:129-33. Medline:21403413 doi:10.4103/0256-4947.77485

58 Stav D, Raz M. Prevalence of chronic obstructive pulmonary disease among smokers aged 45 and up in Israel. Isr Med Assoc J. 2007;9:800-2. Medline:18085037

59 Weiss G, Steinacher I, Lamprecht B, Schirnhofer L, Kaiser B, Sonnichsen A, et al. Detection of chronic obstructive pulmonary disease in primary care in Salzburg, Austria: findings from the real world. Respiration. 2014;87:136-43. Medline:24296512 doi:10.1159/000354796

60 Schirnhofer L, Lamprecht B, Vollmer WM, Allison MJ, Studnicka M, Jensen RL, et al. COPD prevalence in Salzburg, Austria: Results from the burden of obstructive lung disease (BOLD) study. Chest. 2007;131:2936. Medline:17218553 doi:10.1378/chest.06-0365

61 Maio S, Sherrill DL, MacNee W, Lange P, Costabel U, Dahlen S-E, et al. The European Respiratory Society spirometry tent: A unique form of screening for airway obstruction. Eur Respir J. 2012;39:1458-67. Medline:22267757 doi:10.1183/09031936.00111910

62 Fabricius P, Lokke A, Marott JL, Vestbo J, Lange P. Prevalence of COPD in Copenhagen. Respir Med. 2011;105:410-7. Medline:20952174 doi:10.1016/j.rmed.2010.09.019

63 Hansen JG, Pedersen L, Overvad K, Omland O, Jensen HK, Sorensen HT. The prevalence of chronic obstructive pulmonary disease among Danes aged 45-84 years: population-based study. COPD. 2008;5:347-52. Medline:19353348 doi:10.1080/15412550802522635

64 Kainu A, Rouhos A, Sovijärvi A, Lindqvist A, Sarna S, Lundbäck B. COPD in Helsinki, Finland: socioeconomic status based on occupation has an important impact on prevalence. Scand J Public Health. 2013;41:5708. Medline:23599377 doi:10.1177/1403494813484554 
65 Jyrki-Tapani K, Sovijarvi A, Lundback B. Chronic obstructive pulmonary disease in Finland: Prevalence and risk factors. COPD. 2005;2:331-9. Medline:17146998 doi:10.1080/15412550500218122

66 Isoaho R, Puolijoki H, Huhti E, Kivelä SL, Laippala P, Tala E. Prevalence of chronic obstructive pulmonary disease in elderly Finns. Respir Med. 1994;88:571-80. Medline:7991881 doi:10.1016/S0954-6111(05)80004-6

67 Kanervisto M, Vasankari T, Laitinen T, Heliövaara M, Jousilahti P, Saarelainen S. Low socioeconomic status is associated with chronic obstructive airway diseases. Respir Med. 2011;105:1140-6. Medline:21459567 doi:10.1016/j.rmed.2011.03.008

68 Roche N, Dalmay F, Perez T, Kuntz C, Vergnenčgre A, Neukirch F, et al. Impact of chronic airflow obstruction in a working population. Eur Respir J. 2008;31:1227-33. Medline:18216058 doi:10.1183/09031936.00089607

69 Geldmacher H, Biller H, Herbst A, Urbanski K, Allison M, Buist AS, et al. The prevalence of chronic obstructive pulmonary disease (COPD) in Germany. Results of the BOLD study. Dtsch Med Wochenschr. 2008;133:2609. Medline:19052996 doi:10.1055/s-0028-1105858

70 Gingter C, Wilm S, Abholz H-H. Is COPD a rare disease? Prevalence and identification rates in smokers aged 40 years and over within general practice in Germany. Fam Pract. 2009;26:3-9. Medline:19033180 doi:10.1093/fampra/cmn084

71 Schikowski T, Sugiri D, Ranft U, Gehring U, Heinrich J, Wichmann H-E, et al. Long-term air pollution exposure and living close to busy roads are associated with COPD in women. Respir Res. 2005;6:152. Medline:16372913 doi:10.1186/1465-9921-6-152

72 Sichletidis L, Tsiotsios I, Gavriilidis A, Chloros D, Kottakis I, Daskalopoulou E, et al. Prevalence of chronic obstructive pulmonary disease and rhinitis in northern Greece. Respiration. 2005;72:270-7. Medline:15942296 doi:10.1159/000085368

73 Minas M, Hatzoglou C, Karetsi E, Papaioannou AI, Tanou K, Tsaroucha R, et al. COPD prevalence and the differences between newly and previously diagnosed COPD patients in a spirometry program. Prim Care Respir J. 2010;19:363-70. Medline:20532466 doi:10.4104/pcrj.2010.00034

74 Benediktsdóttir B, Gudmundsson G, Jorundsdottir KB, Vollmer W, Gíslason T. Prevalence of COPD in Iceland - the BOLD study. Laeknabladid. 2007;93:471-7. Medline:17541146

75 Viegi G, Pistelli F, Sherrill DL, Maio S, Baldacci S, Carrozzi L. Definition, epidemiology and natural history of COPD. Eur Respir J. 2007;30:993-1013. Medline:17978157 doi:10.1183/09031936.00082507

76 Vanfleteren LEGW, Franssen FME, Wesseling G, Wouters EFM. The prevalence of chronic obstructive pulmonary disease in Maastricht, the Netherlands. Respir Med. 2012;106:871-4. Medline:22349067 doi:10.1016/j.rmed.2012.01.008

77 van Durme YMTA, Verhamme KMC, Stijnen T, van Rooij FJA, Van Pottelberge GR, Hofman A, et al. Prevalence, incidence, and lifetime risk for the development of COPD in the elderly: The Rotterdam study. Chest. 2009;135:368-77. Medline:19201711 doi:10.1378/chest.08-0684

78 Afonso ASM, Verhamme KMC, Sturkenboom MCJM, Brusselle GGO. COPD in the general population: Prevalence, incidence and survival. Respir Med. 2011;105:1872-84. Medline:21852081 doi:10.1016/j. rmed.2011.06.012

79 Waatevik M, Skorge TD, Omenaas E, Bakke P, Gulsvik A, Johannessen A. Increased prevalence of chronic obstructive pulmonary disease in a general population. Respir Med. 2013;107:1037-45. Medline:23680166 doi:10.1016/j.rmed.2013.04.008

80 Hvidsten SC, Storesund L, Wentzel-Larsen T, Gulsvik A, Lehmann S. Prevalence and predictors of undiagnosed chronic obstructive pulmonary disease in a Norwegian adult general population. Clin Respir J. 2010;4:13-21. Medline:20298413 doi:10.1111/j.1752-699X.2009.00137.x

81 Bakke PS, Baste V, Hanoa R, Gulsvik A. Prevalence of obstructive lung disease in a general population: Relation to occupational title and exposure to some airborne agents. Thorax. 1991;46:863-70. Medline:1792631 doi:10.1136/thx.46.12.863

82 Johannessen A, Omenaas E, Bakke P, Gulsvik A. Incidence of GOLD - defined chronic obstructive pulmonary disease in a general adult population. Int J Tuberc Lung Dis. 2005;9:926-32. Medline:16104642

83 Bednarek M, Maciejewski J, Wozniak M, Kuca P, Zielinski J. Prevalence, severity and underdiagnosis of COPD in the primary care setting. Thorax. 2008;63:402-7. Medline:18234906 doi:10.1136/thx.2007.085456

84 Nizankowska-Mogilnicka E, Mejza F, Buist AS, Vollmer WM, Skucha W, Harat R, et al. Prevalence of COPD and tobacco smoking in Malopolska region - results from the BOLD study in Poland. Pol Arch Med Wewn. 2007;117:402-10. Medline:18062562

85 Plywaczewski R, Bednarek M, Jonczak L, Zielinski J. Prevalence of COPD in Warsaw population. Pneumonol Alergol Pol. 2003;71:329-35. Medline:15052966

86 Paprzycki P, Panasiuk L, Sodolski W. Prevalence of obstructive respiratory disorders in the rural population of the Lublin region. Ann Univ Mariae Curie Sklodowska Med. 2003;58:72-8. Medline:15314962

87 Siatkowska H, Kozielski J, Ziora D. Chronic obstructive pulmonary disease patients in the general practice. Pneumonol Alergol Pol. 2010;78:112-20. Medline:20306422

88 Bárbara C, Rodrigues F, Dias H, Cardoso J, Almeida J, Matos M, et al. Chronic obstructive pulmonary disease prevalence in Lisbon, Portugal: The burden of obstructive lung disease study. Rev Port Pneumol. 2013;19:96105. Medline:23664024 doi:10.1016/j.rppneu.2012.11.004 
89 Cardoso J, Ferreira JR, Almeida J, Santos JM, Rodrigues F, Matos MJ, et al. Chronic obstructive pulmonary disease in Portugal: Pneumobil (1995) and 2002 prevalence studies revisited. Rev Port Pneumol. 2013;19:8895. Medline:23639349 doi:10.1016/j.rppneu.2012.11.005

90 Mascarenhas J, Falcao H, Lourenco P, Paulo C, Patacho M, Bettencourt P, et al. Population-based study on the prevalence of spirometric obstructive pattern in Porto, Portugal. Respir Care. 2011;56:619-25. Medline:21276282 doi:10.4187/respcare.00698

91 Grzetic-Romcevic T, Devcic B, Sonc S. Spirometric testing on World COPD Day. Int J Chron Obstruct Pulmon Dis. 2011;6:141-6. Medline:21468166 doi:10.2147/COPD.S16605

92 Miravitlles M, Soriano JB, Garcia-Rio F, Munoz L, Duran-Tauleria E, Sanchez G, et al. Prevalence of COPD in Spain: impact of undiagnosed COPD on quality of life and daily life activities. Thorax. 2009;64:863-8. Medline:19553233 doi:10.1136/thx.2009.115725

93 Peńa VS, Miravitlles M, Gabriel R, Jimenez-Ruiz CA, Villasante C, Masa JF, et al. Geographic variations in prevalence and underdiagnosis of COPD: results of the IBERPOC multicentre epidemiological study. Chest. 2000;118:981-9. Medline:11035667 doi:10.1378/chest.118.4.981

94 Cabrera López C, Julia Serda G, Cabrera Lacalzada C, Martin Medina A, Gullon Blanco JA, Garcia Bello MA, et al. Prevalence of chronic obstructive pulmonary disease in the Canary Islands. Arch Bronconeumol. 2014;50:272-7. Medline:24507558 doi:10.1016/j.arbres.2013.12.006

95 Danielsson P, Olafsdottir I, Benediktsdottir B, Gislason T, Janson C. The prevalence of chronic obstructive pulmonary disease in Uppsala, Sweden - the Burden of Obstructive Lung Disease (BOLD) study: cross-sectional population-based study. Clin RespirJ. 2012;6:120-7. Medline:21651748 doi:10.1111/j.1752-699X.2011.00257.x

96 Lindberg A, Bjerg A, Ronmark E, Larsson L-G, Lundback B. Prevalence and underdiagnosis of COPD by disease severity and the attributable fraction of smoking: Report from the Obstructive Lung Disease in Northern Sweden Studies. Respir Med. 2006;100:264-72. Medline:15975774 doi:10.1016/j.rmed.2005.04.029

97 Lindberg A, Jonsson AC, Ronmark E, Lundgren R, Larsson LG, Lundback B. Prevalence of chronic obstructive pulmonary disease according to BTS, ERS, GOLD and ATS criteria in relation to doctor's diagnosis, symptoms, age, gender, and smoking habits. Respiration. 2005;72:471-9. Medline:16210885 doi:10.1159/000087670

98 Ekberg-Aronsson M, Lofdahl K, Nilsson J-A, Lofdahl C-G, Nilsson PM. Hospital admission rates among men and women with symptoms of chronic bronchitis and airflow limitation corresponding to the GOLD stages of chronic obstructive pulmonary disease - A population-based study. Respir Med. 2008;102:109-20. Medline:17928213 doi:10.1016/j.rmed.2007.07.028

99 Lindström M, Jonsson E, Larsson K, Lundback B. Underdiagnosis of chronic obstructive pulmonary disease in Northern Sweden. Int J Tuberc Lung Dis. 2002;6:76-84. Medline:11931405

100 Hasselgren M, Arne M, Lindahl A, Janson S, Lundback B. Estimated prevalences of respiratory symptoms, asthma and chronic obstructive pulmonary disease related to detection rate in primary health care. Scand J Prim Health Care. 2001;19:54-7. Medline:11303549 doi:10.1080/028134301300034701

101 Larsson M. Where is the borderline between asthma and "COPD"? Reflections on a diagnostic questionnaire. Lakartidningen. 1995;92:1089-92. Medline:7700110

102 Bridevaux P-O, Probst-Hensch NM, Schindler C, Curjuric I, Felber Dietrich D, Braendli O, et al. Prevalence of airflow obstruction in smokers and never-smokers in Switzerland. Eur Respir J. 2010;36:1259-69. Medline:20413537 doi:10.1183/09031936.00004110

103 Arslan Z, Ilgazli A, Etiler N, Hamzaoglu O. Prevalence of chronic obstructive pulmonary disease in Kocaeli: an industrialised city in Turkey. Balkan Med J. 2013;30:387-93. Medline:25207146 doi:10.5152/balkanmedj.2013.8042

104 Erdogan A, Yilmazel-Ucar E, Araz O, Saglam L, Mirici NA. Contribution of spirometry to early diagnosis of chronic obstructive pulmonary disease in primary health care centers. Turk J Med Sci. 2013;43:690-4. doi:10.3906/sag-1207-60

105 Deveci F, Deveci SE, Turkoglu S, Turgut T, Kirkil G, Rahman S, et al. The prevalence of chronic obstructive pulmonary disease in Elazig, Eastern Turkey. Eur J Intern Med. 2011;22:172-6. Medline:21402248 doi:10.1016/j.ejim.2010.12.014

106 Gunen H, Hacievliyagil SS, Yetkin O, Gulbas G, Mutlu LC, Pehlivan E. Prevalence of COPD: first epidemiological study of a large region in Turkey. Eur J Intern Med. 2008;19:499-504. Medline:19013377 doi:10.1016/j. ejim.2007.06.028

107 Jordan RE, Miller MR, Lam K-BH, Cheng KK, Marsh J, Adab P. Sex, susceptibility to smoking and chronic obstructive pulmonary disease: the effect of different diagnostic criteria. Analysis of the Health Survey for England. Thorax. 2012;67:600-5. Medline:22382600 doi:10.1136/thoraxjnl-2011-201384

108 Melville AM, Pless-Mulloli T, Afolabi OA, Stenton SC. COPD prevalence and its association with occupational exposures in a general population. Eur Respir J. 2010;36:488-93. Medline:20110401 doi:10.1183/09031936.00038309

109 Murtagh E, Heaney L, Gingles J, Shepherd R, Kee F, Patterson C, et al. The prevalence of obstructive lung disease in a general population sample: The NICECOPD study. Eur J Epidemiol. 2005;20:443-53. Medline:16080593 doi:10.1007/s10654-005-1248-8

110 Dickinson JA, Meaker M, Searle M, Ratcliffe G. Screening older patients for obstructive airways disease in a semi-rural practice. Thorax. 1999;54:501-5. Medline:10335003 doi:10.1136/thx.54.6.501 
111 Renwick DS, Connolly MJ. Prevalence and treatment of chronic airways obstruction in adults over the age of 45. Thorax. 1996;51:164-8. Medline:8711649 doi:10.1136/thx.51.2.164

112 Shahab L, Jarvis MJ, Britton J, West R. Prevalence, diagnosis and relation to tobacco dependence of chronic obstructive pulmonary disease in a nationally representative population sample. Thorax. 2006;61:1043-7. Medline:17040932 doi:10.1136/thx.2006.064410

113 de Marco R, Accordini S, Cerveri I, Corsico A, Sunyer J, Neukirch F, et al. An international survey of chronic obstructive pulmonary disease in young adults according to GOLD stages. Thorax. 2004;59:120-5. Medline:14760151 doi:10.1136/thorax.2003.011163

114 Zachariades AG, Zachariadou T, Adamide T, Anagnostopoulou U, Georgiou A, Gourgoulianis KI. Prevalence of chronic obstructive pulmonary disease in Cyprus: A population-based study. COPD. 2012;9:259-67. Medline:22432899 doi:10.3109/15412555.2011.650242

115 Islam MSHM, Pasha MM, Azad AK, Murshed KM. Prevalence and risk factors of chronic obstructive pulmonary disease (COPD) in Dhaka city population. Mymensingh Med J. 2013;22:547-51. Medline:23982547

116 Mosharraf-Hossain KM, Islam S, Kalam A, Pasha M, Sultana F, Hossain R, et al. Detection of chronic obstructive pulmonary disease using spirometric screening. Mymensingh Med J. 2009;18:S108-12. Medline:19377418

117 Maranetra KN, Dejsomritrutai W, Nana A, Naruman C, Sangkaew S, Aksornin M, et al. The prevalence and incidence of COPD among urban older persons of Bangkok Metropolis. J Med Assoc Thai. 2002;85:114755. Medline: 12546310

118 Parasuramalu BG, Huliraj N, Prashanth Kumar S, Gangaboraiah S, Ramesh Masthi N, Srinivasa Babu C. Prevalence of chronic obstructive pulmonary disease and its association with tobacco smoking and environmental tobacco smoke exposure among rural population. Indian J Public Health. 2014;58:45-9. Medline:24748357 doi:10.4103/0019-557X.128166

119 Johnson P, Balakrishnan K, Ramaswamy P, Ghosh S, Sadhasivam M, Abirami O, et al. Prevalence of chronic obstructive pulmonary disease in rural women of Tamilnadu: implications for refining disease burden assessments attributable to household biomass combustion. Glob Health Action. 2011;4:7226. Medline:22065945

120 Mahesh PA, Jayaraj B, Prahlad S, Chaya S, Prabhakar A, Agarwal A, et al. Validation of a structured questionnaire for COPD and prevalence of COPD in rural area of Mysore: A pilot study. Lung India. 2009;26:63-9. Medline:20442838 doi:10.4103/0970-2113.53226

121 Toelle BG, Xuan W, Bird TE, Abramson MJ, Atkinson DN, Burton DL, et al. Respiratory symptoms and illness in older Australians: the Burden of Obstructive Lung Disease (BOLD) study. Med J Aust. 2013;198:1448. Medline:23418694 doi:10.5694/mjal1.11640

122 Matheson MC, Benke G, Raven J, Sim MR, Kromhout H, Vermeulen R, et al. Biological dust exposure in the workplace is a risk factor for chronic obstructive pulmonary disease. Thorax. 2005;60:645-51. Medline:16061705 doi:10.1136/thx.2004.035170

123 Shirtcliffe P, Weatherall M, Marsh S, Travers J, Hansell A, McNaughton A, et al. COPD prevalence in a random population survey: a matter of definition. Eur Respir J. 2007;30:232-9. Medline:17666557 doi:10.1183/09031936.00157906

124 Liu SM, Wang XP, Wang DL, Zhou YM, Lu JC, Zheng JP, et al. Epidemiologic analysis of COPD in Guangdong province. Zhonghua Yi Xue Za Zhi. 2005;85:747-52. Medline:15949380

125 Zhong N, Yao W, Chen P, Kang J, Huang S, Chen B, et al. Prevalence of chronic obstructive pulmonary disease in China: A large, population-based survey. Am J Respir Crit Care Med. 2007;176:753-60. Medline:17575095 doi:10.1164/rccm.200612-17490C

126 Qiu J, Zhang Y, Chen J, Luo T, Yu X, Wang J, et al. Prevalence of chronic obstructive pulmonary disease in Ningxia Hui Autonomous Region of China. Zhonghua Jie He He Hu Xi Za Zhi. 2013;36:265-8. Medline:23945339

127 Li Q, Liao X, Zhang Q, Wang Y, Wu X, Xu Z, et al. Epidemiological sampling survey on chronic obstructive pulmonary disease in urban area of Chongqing. Chin J Respir Crit Care Med. 2009;8:12-5.

128 Gong Y, Shi G-C, Wan H-Y, Li M, Li Q-Y, Cheng Q-J, et al. Changes in prevalences of COPD within 5 years in people aged no less than 60 years in Shanghai urban area. J Shanghai Jiaotong Univ. 2011;31:216. Med Sci.

129 Ling M, Gou AS, Niu L, Wang H, Abaydulla Z, Zhu J, et al. The risk factors for chronic obstructive pulmonary disease in Xinjiang rural areas. Zhonghua Jie He He Hu Xi Za Zhi. 2011;34:666-8. Medline:22177491

130 Zeng X-F, Che F, Wang X-X. Diagnosis and treatment of chronic obstructive pulmonary disease by general practitioners working in community hospitals of Chengdu. Chin Gen Pract. 2010;28:2010-28.

131 Liu S, Wen D, Li L, Li Z. An epidemiological study of chronic obstructive pulmonary disease in greenhouse farmers in Liaoning Province from 2006 to 2009. Zhonghua Jie He He Hu Xi Za Zhi. 2011;34:753-6. Medline:22321709

132 Liu S, Zhou Y, Wang X, Wang D, Lu J, Zheng J, et al. Biomass fuels are the probable risk factor for chronic obstructive pulmonary disease in rural South China. Thorax. 2007;62:889-97. Medline:17483137 doi:10.1136/thx.2006.061457

133 Yu LZ, Feng YP, Mu HJ, Liu L, Yu LY, Li YX, et al. Mortality trend on chronic obstructive pulmonary disease in Liaoning province, 1984-2010. Zhonghua Liu Xing Bing Xue Za Zhi. 2012;33:399-403. Medline:22781414 
134 Wang X-P, Zhou Y-M, Zeng X-Y, Liu S-M, Qiu R, Xie J-F, et al. Study on the prevalence rate of chronic obstructive pulmonary disease in northern part of Guangdong province. Zhonghua Liu Xing Bing Xue Za Zhi. 2005;26:211-3. Medline:15941513

135 Jiang RG, Luo D, Huang C, Li W. Study on the prevalence rate and risk factors of chronic obstructive pulmonary disease in rural community population in Hubei province. Zhonghua Liu Xing Bing Xue Za Zhi. 2007;28:976-9. Medline:18399143

136 Yao W-Z, Zhu H, Shen N, Han X, Liang Y-J, Zhang L-Q, et al. Epidemiological data of chronic obstructive pulmonary disease in Yanqing County in Beijing. Beijing Da Xue Xue Bao. 2005;37:121-5. Medline:15841136

137 Wang Y-C, Lin J-M, Li C-Y, Lee L-T, Guo Y-L, Sung F-C. Prevalence and risks of chronic airway obstruction: A population cohort study in Taiwan. Chest. 2007;131:705-10. Medline:17356083 doi:10.1378/chest.06-1829 Yin P, Jiang CQ, Cheng KK, Lam TH, Lam KH, Miller MR, et al. Passive smoking exposure and risk of COPD among adults in China: the Guangzhou Biobank Cohort Study. Lancet. 2007;370:751-7. Medline:17765524 doi:10.1016/S0140-6736(07)61378-6

139 Smith M, Li L, Augustyn M, Kurmi O, Chen J, Collins R, et al. Prevalence and correlates of airflow obstruction in 317000 never-smokers in China. Eur Respir J. 2014;44:66-77. Medline:24603814 doi:10.1183/09031936.00152413

140 Zhou Y, Wang C, Yao W, Chen P, Kang J, Huang S, et al. COPD in Chinese nonsmokers. Eur Respir J. 2009;33:509-18. Medline:19251797

141 Ko FWS, Woo J, Tam W, Lai CKW, Ngai J, Kwok T, et al. Prevalence and risk factors of airflow obstruction in an elderly Chinese population. Eur RespirJ. 2008;32:1472-8. Medline:18684847 doi:10.1183/09031936.00058708

142 Lau AC-W, Ip MS-M, Lai CK-W, Choo K-L, Tang K-S, Yam LY-C, et al. Variability of the prevalence of undiagnosed airflow obstruction in smokers using different diagnostic criteria. Chest. 2008;133:42-8. Medline:17989159 doi:10.1378/chest.07-1434

143 Nishimura K, Mitsuma S, Kobayashi A, Yanagida M, Nakayasu K, Hasegawa Y, et al. COPD and disease-specific health status in a working population. Respir Res. 2013;14:61. Medline:23725096 doi:10.1186/14659921-14-61

144 Fukahori S, Matsuse H, Takamura N, Hirose H, Tsuchida T, Kawano T, et al. Prevalence of chronic obstructive pulmonary diseases in general clinics in terms of FEV1/FVC. Int J Clin Pract. 2009;63:269-74. Medline: 19196365 doi:10.1111/j.1742-1241.2008.01873.x

145 Takemura H, Hida W, Sasaki T, Sugawara T, Sen T. Prevalence of chronic obstructive pulmonary disease in Japanese people on medical check-up. Tohoku J Exp Med. 2005;207:41-50. Medline:16082154 doi:10.1620/ tjem.207.41

146 Fukuchi Y, Nishimura M, Ichinose M, Adachi M, Nagai A, Kuriyama T, et al. COPD in Japan: the Nippon COPD epidemiology study. Respirology. 2004;9:458-65. Medline:15612956 doi:10.1111/j.1440-1843.2004.00637.x

147 Kojima S, Sakakibara H, Motani S, Hirose K, Mizuno F, Ito M, et al. Effects of smoking and age on chronic obstructive pulmonary disease in Japan. J Epidemiol. 2005;15:113-7. Medline:16141629 doi:10.2188/ jea.15.113

148 Yoo KH, Kim YS, Sheen SS, Park JH, Hwang YI, Kim S-H, et al. Prevalence of chronic obstructive pulmonary disease in Korea: The fourth Korean National Health and Nutrition Examination Survey, 2008. Respirology. 2011;16:659-65. Medline:21342331 doi:10.1111/j.1440-1843.2011.01951.x

149 Kim SJ, Suk MH, Choi HMA, Kimm KC, Jung KH, Lee SY, et al. The local prevalence of COPD by post-bronchodilator GOLD criteria in Korea. Int J Tuberc Lung Dis. 2006;10:1393-8. Medline:17167958

150 Kim DS, Kim YS, Jung K-S, Chang JH, Lim C-M, Lee JH, et al. Prevalence of chronic obstructive pulmonary disease in Korea. Am J Respir Crit Care Med. 2005;172:842-7. Medline:15976382 doi:10.1164/rccm.200502$2590 \mathrm{C}$

151 Shin C, Lee S, Abbott RD, Kim JH, Lee SY, In KH, et al. Relationships between respiratory symptoms and FEV1 in men and women with normal lung function: The Korean Health and Genome Study. Lung. 2005;183:301-9. Medline:16389723 doi:10.1007/s00408-004-2543-y

152 Fishwick D, Bradshaw LM, D'Souza W, Town I, Armstrong R, Pearce N, et al. Chronic bronchitis, shortness of breath, and airway obstruction by occupation in New Zealand. Am J Respir Crit Care Med. 1997;156:14406. Medline:9372658 doi:10.1164/ajrccm.156.5.97-03007

153 Idolor LF, De Guia TS, Francisco NA, Roa CC, Ayuyao FG, Tady CZ, et al. Burden of obstructive lung disease in a rural setting in the Philippines. Respirology. 2011;16:1111-8. Medline:21801277 doi:10.1111/ j.1440-1843.2011.02027.x

154 Lâm HT, Ekerljung L, Tng NV, Ronmark E, Larsson K, Lundback B. Prevalence of COPD by disease severity in men and women in Northern Vietnam. COPD. 2014;11:575-81. Medline:24867392 doi:10.3109/15412 555.2014 .898039

155 Ko FWS, Lai CKW, Woo J, Ho SC, Ho CWM, Goggins W, et al. 12-year change in prevalence of respiratory symptoms in elderly Chinese living in Hong Kong. Respir Med. 2006;100:1598-607. Medline:16446081 doi:10.1016/j.rmed.2005.12.007

156 United Nations. World Population Prospects: The 2012 Revision. New York: United Nations, 2013. Available from: http://esa.un.org/wpp/.

157 World Health Organization. The World Health Report 2002: reducing risks, promoting healthy life. Geneva, Switzerland: WHO, 2002. 
158 Regional COPD Working Group. COPD prevalence in 12 Asia-Pacific countries and regions: Projections based on the COPD prevalence estimation model. Respirology. 2003;8:192-8. Medline:12753535 doi:10.1046/ j.1440-1843.2003.00460.x

159 Chan-Yeung M, Ait-Khaled N, White N, Ip M, Tan W. The burden and impact of COPD in Asia and Africa. Int J Tuberc Lung Dis. 2004;8:2-14. Medline:14974740

160 McKay AJ, Mahesh PA, Fordham JZ, Majeed A. Prevalence of COPD in India: a systematic review. Prim Care Respir J. 2012;21:313-21. Medline:22790612 doi:10.4104/pcrj.2012.00055

161 European Commission. European Health Interview Survey: Descripion of dataset, 2014. Available from: http:// ec.europa.eu/eurostat/web/microdata/european-health-interview-survey.

162 Pauwels RA, Buist AS, Calverley PMA, Jenkins CR, Hurd SS. Global strategy for the diagnosis, management, and prevention of chronic obstructive pulmonary disease. Am J Respir Crit Care Med. 2001;163:1256-76. Medline:11316667 doi:10.1164/ajrccm.163.5.2101039

163 van Gemert F, van der Molen T, Jones R, Chavannes N. The impact of asthma and COPD in sub-Saharan Africa. Prim Care Respir J. 2011;20:240-8. Medline:21509418 doi:10.4104/pcrj.2011.00027

164 Finney LJ, Feary JR, Leonardi-Bee J, Gordon SB, Mortimer K. Chronic obstructive pulmonary disease in subSaharan Africa: A systematic review. Int J Tuberc Lung Dis. 2013;17:583-9. Medline:23394105 doi:10.5588/ ijtld.12.0619

165 Ben Abdallah FC, Taktak S, Chtourou A, Mahouachi R, Kheder AB. Burden of chronic respiratory diseases (CRD) in Middle East and North Africa (MENA). WAO Journal. 2011;4:S6-8. Medline:23283069

166 Lopez Varela MV, Montes de Oca M, Halbert RJ, Muino A, Perez-Padilla R, Talamo C, et al. Sex-related differences in COPD in five Latin American cities: the PLATINO study. Eur Respir J. 2010;36:1034-41. Medline:20378599 doi:10.1183/09031936.00165409

167 Walker PP, Mitchell P, Diamantea F, Warburton CJ, Davies L. Effect of primary-care spirometry on the diagnosis and management of COPD. Eur Respir J. 2006;28:945-52. Medline:16870668 doi:10.1183/0903193 6.06 .00019306

168 Stoilkova A, Janssen DJ, Wouters EF. Educational programmes in COPD management interventions: a systematic review. Respir Med. 2013;107:1637-50. Medline:24012387 doi:10.1016/j.rmed.2013.08.006 